\title{
Mortars for 3D printing
}

\author{
Olga Demyanenko ${ }^{1, *}$, Ekaterina Sorokina ${ }^{1}$, Natalya Kopanitsa ${ }^{1}$, and Yurij Sarkisov ${ }^{1}$ \\ ${ }^{1}$ Tomsk State University of Architecture and Building, 634003 Tomsk, Russia
}

\begin{abstract}
The paper is aimed at developing scientifically proven compositions of mortars for 3D printing modified by a peat-based admixture with improved operational characteristics. The paper outlines the results of experimental research on hardened cement paste and concrete mixture with the use of modifying admixture MT-600 (thermally modified peat). It is found that strength of hardened cement paste increases at early age when using finely dispersed admixtures, which is the key factor for formation of construction and technical specifications of concrete for 3D printing technologies. The composition of new formations of hardened cement paste modified by MT-600 admixture were obtained, which enabled to suggest the possibility of their physico-chemical interaction while hardening.
\end{abstract}

\section{Introduction}

Today, the construction industry faces a number of serious problems, such as: low labor efficiency, high statistical rate of emergencies on construction sites, complications of performing control of construction processes. Besides, construction industry is one of the main consumers of non-renewable natural resources [1].

Adaptive technologies opened new opportunities to many dynamically developing branches of industrial production. 3D printing brought technologies to the new level due to their versatility; they are also widely used in construction [2-10]. Compared to traditional ones, 3D technologies enable complete automation of the process, reduce the amount of waste, improve sustainability of construction and architectural expressiveness of structures, as well as provide solidity of structures due to continuous layer-by-layer application. The advantage of such technologies is high speed of construction, for example, Shanghai company WinSun constructed 10 single-floor houses $200 \mathrm{~m}^{2}$ each using a 3D printer in one day $[11,12]$.

In order to apply adaptive technology in construction the recent achievements in the field of material science shall be used. For construction of real buildings and structures using 3D printing special fine-grained concretes (mortars) are required, which can provide safe exploitation of buildings, their robustness and durability. These issues today are not sufficiently studied. Traditional concrete based on cement does not meet the requirements to the materials for constructive 3D printing [13].

To optimize the 3D printing process 2 conditions shall be accounted. First, the adhesion between layers decreases with the increase of time interval between deposing layers [14].

\footnotetext{
*Corresponding author: demyanenko.olga.v@gmail.com
} 
Second, concrete mixture shall develop sufficient initial strength to bear the following layer without deforming. The need in setting of previously printed layers can slow down the construction. Comparison of these two limitations leads to the paradox of 3D printing speed optimization. The time interval between the two set layers shall be, on the one hand, long enough for providing the required strength, and on the other hand, short enough for providing good adhesion between the layers [15].

In this regard, a conclusion can be made that mortar for $3 \mathrm{D}$ printing shall have the following characteristics: high strength at early age, fast setting, cohesion, sufficient yielding stress (to bear the load with layer-by-layer construction). In order to provide these characteristics, scientifically proven compositions of concrete mixtures shall be developed with the use of complex modifying admixtures. The research results on the impact of effective modifying admixtures based on local peat materials can be relevant [16].

The purpose of this study is development of scientifically proven compositions of mortars for $3 \mathrm{D}$ printing modified by a peat-based admixture with improved operational characteristics.

\section{Selection of admixture}

The wide range of application properties of concrete mortars for $3 \mathrm{D}$ printing is caused by the need to use a complex of modifying admixtures with different purposes. Production of import-substituting admixtures to building mortars competitive in terms of their properties is relevant for Russia; it can be provided by manufacturing of modifying admixtures based on local raw materials. The resources of Siberian region (Russia) enable producing admixtures based on peat, which also allows managing properties of building mixtures and mortars for 3D printing. Stock of this partially renewable resource in Tomsk region is 29.3 bn tons with regard to $40 \%$ humidity. Tomsk region occupies the second position in Russia in terms of peat stock.

Material composition of peat is represented by various organic and mineral compounds. Due to the presence of chemically active organo-mineral functional groups it can be used for various techniques of raw material modification: thermal, chemical, mechanical or a combination of several types for obtaining products for various purposes, including admixtures for building mixtures.

To perform this research a modifying admixture (MT-600) was prepared in a laboratory by thermal anaerobic activation of peat, which corresponds to the technique of lowtemperature carbonization. Pyrolysis of the source materials was performed with the use of specially developed apparatus at the temperature of $600^{\circ} \mathrm{C}$ [17]. The obtained admixture is a hydrophobic finely dispersed consistent powder of a dark-gray color. Physico-chemical studies of this admixture demonstrate that the element composition of thermal modified peat is represented mainly be silicone, aluminum, carbon and calcium, which corresponds to the data on the composition of mineral part of peat.

The results of electron microscopy analysis showed that the MT-600 admixture contains also nano-size elements which are nano-carbons of various shapes, such as fullerenes sized $5 \mathrm{~nm}$ and bigger, nanotubes and nanofibers sized up to $200 \mathrm{~nm}$ and more with the crosswise size of $20 \mathrm{~nm}$ and less [17].

According to the experimental data in [18-23], the nano-dispersed particles are most efficient in compound materials when added in microdoses.

It was found that the average size of a peat admixture particle is $(98 \pm 5)$ microns. Specific surface area of the obtained admixture is $0.6 \mathrm{~m}^{2} / \mathrm{g}$. It is known that the most part of modifying admixtures in compound materials based on cement react with binder by controlling their surface properties or densifying the structure of cement systems. To define the reasonable cement-admixture ratio the finely dispersed substance obtained after thermal 
treatment of peat was mixed with cement in the amount of $0.25 ; 0.5 ; 0.75 \%$ of cement weight. Dry components were mixed first, after which the mixture was activated by water. Water-cement ratio was correspondent to the standard concentration and equaled 0.28. Compressive strength of the hardened cement paste was defined in cubic samples 20x20x20 mm in size, at the age of 7, 14 and 28 days. Each series of experiments included at least 5 samples. Coefficient of strength variation is no more than $5.2 \%$.

Figure 1 demonstrates the research results on the impact of the MT-600 admixture on strength of hardened cement paste. It is showed that the reasonable content of modifying admixture shall be $0.5 \%$ of cement weight. Adding the admixture in the amount less than $0.5 \%$ of cement weight does not provide the required result.

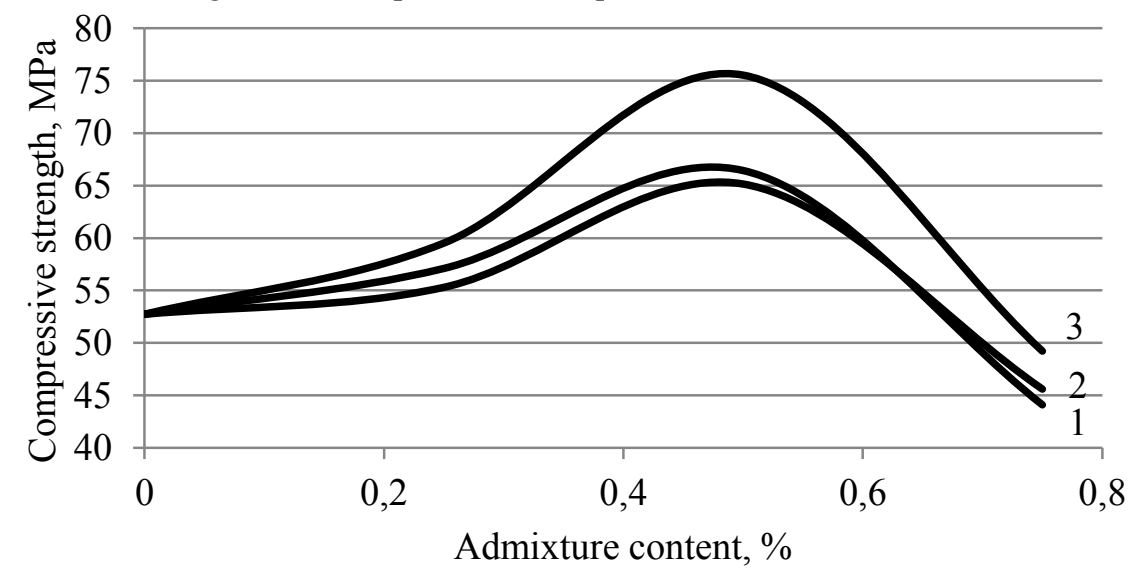

Fig. 1. Impact of MT-600 admixture on compressive strength of hardened cement paste: 1 - hardened cement paste modified by admixture based on peat of Kandinskoe deposit; 2 - hardened cement paste modified by admixture based on peat of Chelbak deposit; 3 - hardened cement paste modified by admixture based on peat of Gusevskoe deposit;

Properties of the end product were found to be greatly dependent on the properties of source materials. Figure 1 demonstrates that the admixture based on peat of Gusevskoe deposit (Tomsk region) provides the best compressive strength properties of the hardened cement paste. It is known that peat obtained from this deposit has higher ash content and the average decomposition grade compared to peats from other deposits. Higher ash content causes high probability of formation of mineral-organic compounds which are the main reason of increase in strength of hardened cement paste. Further investigation was performed with the use of peat of Gusevskoe deposit [17].

\section{Materials and Methods}

The following materials were used during the study: Portland cement of grade CEM I 42.5H (ЦЕM I 42,5H) corresponding to GOST 31108-2016 and construction sand corresponding to GOST 8736-2014. To investigate the properties of cement-sand mortars modified by MT-600 admixture the cubic samples sized $70.7 \times 70.7 \times 70.7 \mathrm{~mm}$ were prepared, the sand:cement ratio was $1: 2$, samples were hardened in air-humid conditions. Strength of samples was evaluated at the age of 3, 7 and 28 days. The following rheological parameters of freshly mixed mortars were investigated: mobility, water retention capacity according to GOST 31356-2007 (Fig. 5). 


\section{Results and discussion}

The impact of polyfraction admixture MT-600 on the properties and concrete mixtures was previously investigated in [18]. However, there has been no research on monofraction admixtures so far. The admixture obtained as a result of pyrolysis and milling were divided by classification into the following fractions: less than $0.08 \mathrm{~mm} ; 0.08-0125 \mathrm{~mm} ; 0.125-0.18$ $\mathrm{mm}$ in the $0.5 \%$ ratio of cement weight; then, they were mixed with dry cement and activated with water. Compressive strength of the modified samples of hardened cement paste was evaluated at the age of 3, 7 and 28 days. The experimental results are given in Table 1.

Table 1. Strength parameters of samples.

\begin{tabular}{|c|c|c|c|c|c|}
\hline \multirow{2}{*}{$\begin{array}{c}\text { Samples } \\
\text { series }\end{array}$} & $\begin{array}{c}\text { MT- } \\
600, \% \\
\text { wt. of } \\
\text { cement }\end{array}$ & \multirow{2}{*}{$\begin{array}{c}\text { water- } \\
\text { cement } \\
\text { ratio }\end{array}$} & 3 days & 7 days & 28 days \\
\cline { 4 - 6 } & - & 0.258 & 40.2 & 50.8 & 57.65 \\
\hline 1 & 0.5 & 0.25 & $49.6(+23 \%)$ & $65.3(+20 \%)$ & $71.9(+24 \%)$ \\
\hline 2 & 0.5 & 0.258 & $60(+49 \%)$ & $63.5(+25 \%)$ & $78.4(+35 \%)$ \\
\hline 3 & 0.5 & 0.26 & $56.7(+41 \%)$ & $75.5(+49 \%)$ & $76.9(+33 \%)$ \\
\hline 4 & 0.5 & 0.268 & $58.5(+45 \%)$ & $76(+50 \%)$ & $77.3(+34 \%)$ \\
\hline 5 & &
\end{tabular}

Series: 1-reference (Cement+Water); 2-Cement+MT-600 (fraction less than $0.08 \mathrm{~mm}$ ); 3Cement+MT-600 (fraction 0.08-0.125 mm); 4-Cement+MT-600 (fraction 0.125$0.180 \mathrm{~mm}$ ); 5-Cement+MT-600 (polyfraction).

According to the obtained data, in samples of hardened cement paste modified with a polyfraction composition strength increase by $34 \%$ is observed on the 28th day of hardening, whereas in hardened cement paste with MT-600 with the fraction of 0.08$0.125 \mathrm{~mm}$ strength increased by $35 \%$ compared to the reference sample. At early age (3 days), strength of hardened cement paste with MT-600 with the fraction of 0.08-0.125 mm is $49 \%$ higher than that of the reference sample. Thus, the use of MT-600 admixture gives cement compositions the ability to develop strength at early age, which is an important feature for 3D printing technologies.

X-ray diffraction analysis was performed to define the composition of new formation in the modified hardened cement paste. Diffractograms were obtained using XRD-6000 diffractometer with $\mathrm{CuK} \alpha$ radiation (Fig. 2, 3). As a result of analyzing hardened cement paste composition performed with the use of the databases PCPDFWIN and PDF-4+, as well as POWDERCELL 2.5 program of full-profile analysis, the peculiarities of structure and composition formation in hardened cement paste modified with MT-600 admixture were determined.

X-ray diffraction analysis of the hydration products of the reference sample and the one modified with MT-600 admixture confirms presence of new crystalline phases in the modified hardened cement paste. When introducing admixtures based on thermally treated peat in hydrated cement, one can observe occurrence of additional peaks of stable hydrated calcium silicate $(\mathrm{d} / \mathrm{n}=7,40 ; 3,04 \AA)$ and low-basic hydrated calcium silicate of type C-S-H $(\mathrm{d} / \mathrm{n}=11,4,94 ; 2,92 ; 2,19 ; 2,09 \AA)$; besides, intensity of peaks in crystalline phases $\mathrm{Ca}(\mathrm{OH})_{2}$ $(\mathrm{d} / \mathrm{n}=4,9 ; 2,63 ; 1,68 ; 1,48 \AA)$ decreases, which causes higher strength of hardened cement paste.

The paper provides the result of investigation on physico-mechanical properties of building mortar based on cement modified with MT-600 admixture with various fractions, 
such as water retention capacity, mobility of mortar mixtures and mortar strength (Fig. 4, 5). The investigation demonstrated that the use of MT-600 admixture reduces water retention capacity of mixtures by $0.2-0.7 \%$ compared to the reference compositions. The obtained results shall be accounted in further research.

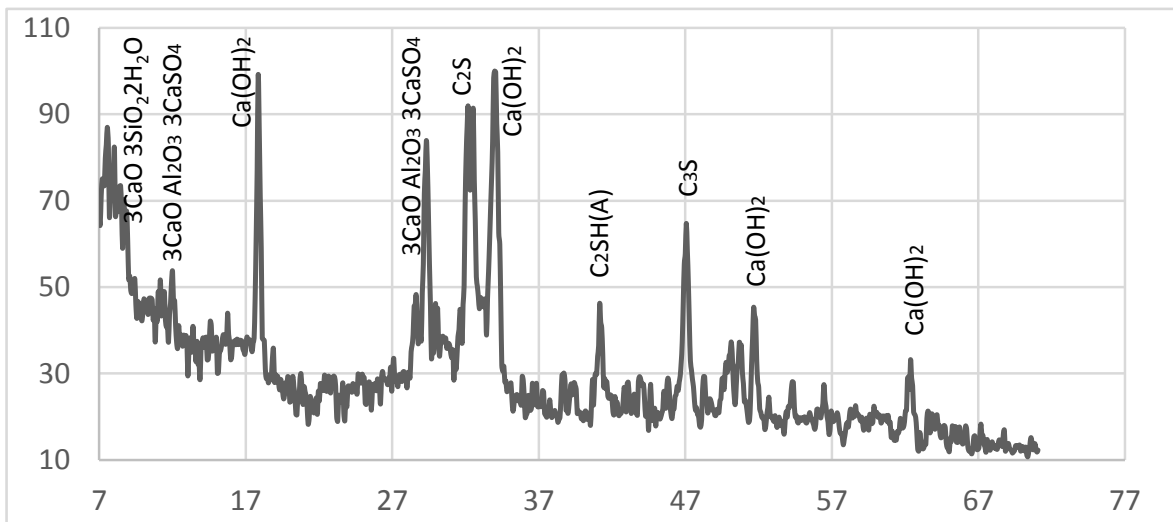

Fig. 2 Diffractogram of hardened cement paste at the age of 28 days: reference sample.

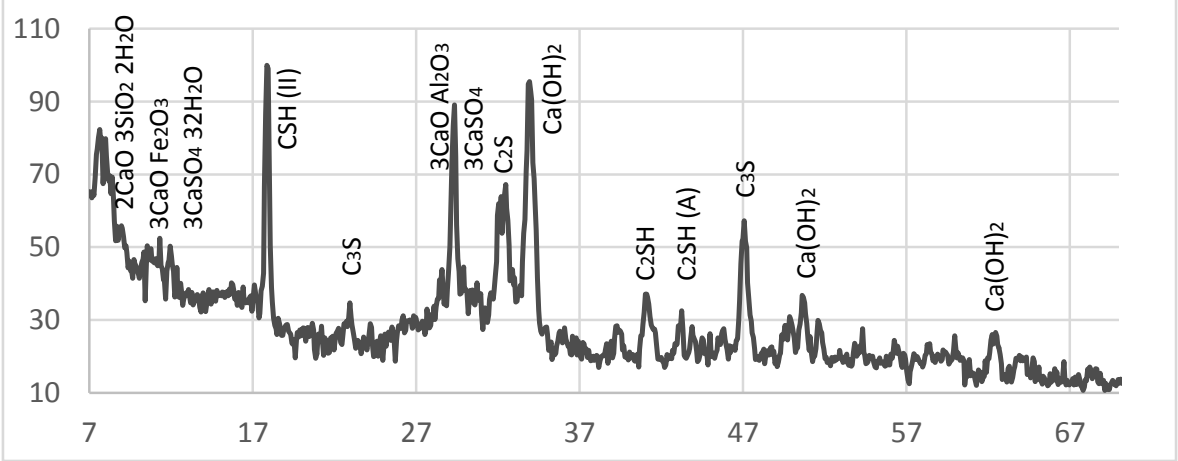

Fig. 3. Diffractogram of hardened cement paste at the age of 28 days: Cement + MT- 600 .

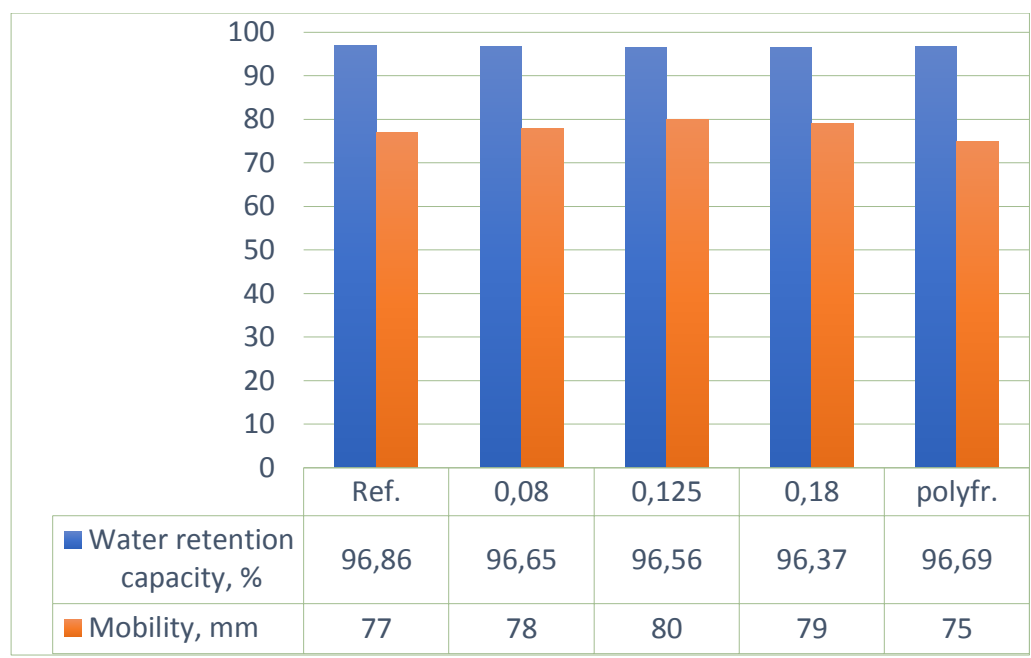

Fig. 4. Water retention capacity and mobility of cement-sand mortars with MT-600 admixture . 
Mobility of mixture increases by $1-4 \%$ compared to the reference sample. The admixture with hydrophobic properties reduces friction between solid particles and by doing so increases the mixture mobility.

The study of impact of peat-based admixtures on strength of cement-sand mixture revealed that even at early age the samples modified with MT-600 admixture with the fraction of $0.125-0.180 \mathrm{~mm}$ showed $20 \%$ higher strength compared to the reference samples. By the age of 28 days strength of samples modified with MT-600 admixture with various fractions increased by $18-25 \%$ in comparison with the reference samples (Fig.5). Maximum strength was observed in samples modified with MT-600 admixtures with the fraction of $0.125-0.180 \mathrm{~mm}$; the addition of strength is $25 \%$. Coefficient of compressive strength variation is no more than $4.6 \%$. Samples modified with MT-600 admixture with polyfraction composition and with the fraction of $0.125-0.180 \mathrm{~mm}$ showed the maximum strength, which enables to conclude that particles larger than $0.125 \mathrm{~mm}$ have strong effect on the structure formation process in hardened cement paste.

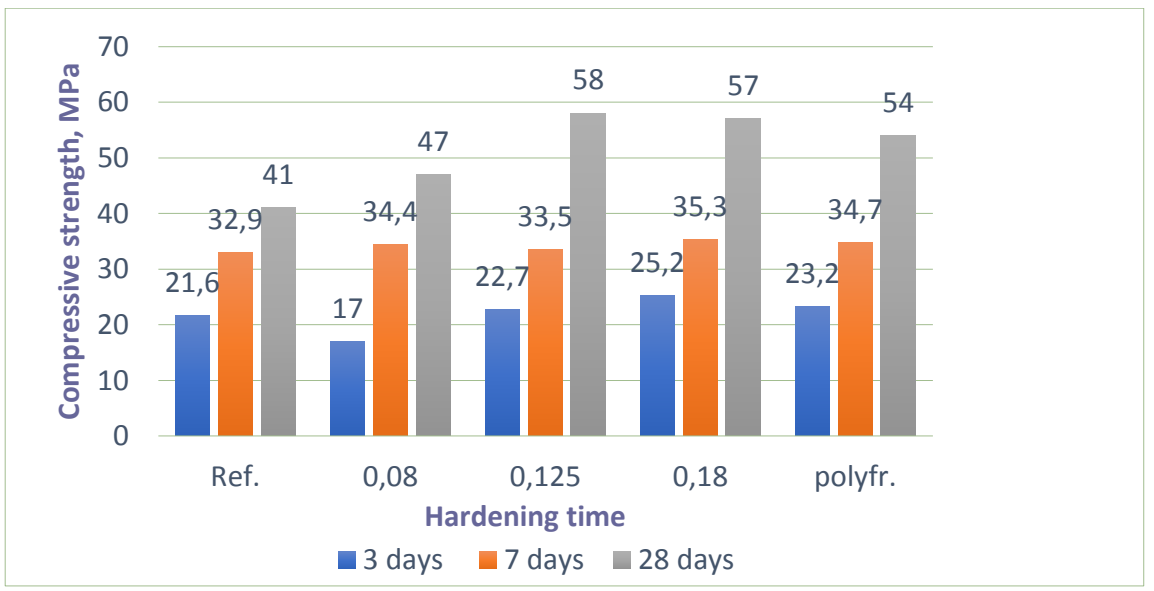

Fig. 5. Strength of concrete with MT-600 admixture at the age of 3, 7 and 28 days.

Strengthening of hardened cement paste when introducing peat-based admixtures can be explained by formation of a denser spatial and organizational hierarchical structure due to directed variation of adsorption and hydration processes, as well as due to kinetics of nucleation. At the same time, development of microcracks in the material slows down, which is connected with the effect of micro-reinforcement and densification of hardened cement paste and stress distribution [24]. Besides, the effectiveness of densifying admixture is caused by formation of additional crystallization centers and high surface energy, which brings about higher hardening rate and higher strength of hardened cement paste [25].

\section{Conclusion}

The paper studies strength parameters of hardened cement paste and hardened mortars for $3 \mathrm{D}$ printing. It is found that the use of MT-600 admixture provides higher strength of hardened cement paste and mortar both at early age and at the age of 28 days. Moreover, the effect of admixture dispersion on the main technological parameters of a composite material was determined. The study demonstrates that it is reasonable to use the MT-600 admixture as a component for obtaining polyfractional admixtures to building mixtures for 3 printing. The obtained results satisfy the initial purpose of the research which is development of building mortars for 3D printing technologies. 
Further research on the impact of peat-based admixtures on the properties of building mortars for 3D printing are relevant, since the use of such admixtures allows reducing costs by decreasing the amount of imported foreign modifiers in the mortars composition. The use of peat as a basis for obtaining modifying admixtures improves the environmental situation of peat producing regions.

\section{References}

1. M.I. Ibrahim, Sustainable Cities and Society, 23, 78-93 (2016)

2. L. Chen, The International Journal of Advanced Manufacturing Technology, 89, 3651-3660 (2017)

3. A.V. Valter, Mining Informational and Analytical Bulletin, 12, (2011), (in Russian)

4. E.N. Kablov, Aviation Materials and Technologies, 5, 7-17 (2012), (in Russian)

5. J.A. Gálvez, 3D Printing and Additive Manufacturing, 3, 160-165 (2016)

6. A. Barazanchi, Journal of Prosthodontics, 26, 156-163 (2016)

7. L.J. Kumar, Advances in 3D Printing \& Additive Manufacturing Technologies, 39-54 (Springer, 2016)

8. M.A. Kreiger, B.A. MacAllister, J.M. Wilhoit, M.P. Case, The Proceedings of the 2015 Conference on Autonomous and Robotic Construction of Infrastructure, 149$158,(2015)$

9. S.H. Huang, P. Liu, A. Mokasdar, L. Hou, The International Journal of Advanced Manufacturing Technology, 67, 1191-1203 (2013)

10. S.A. Udodov, F.A. Belov, A.E. Zolotukhina, Sbornik statej pobeditelej VI Mezhdunarodnoj nauchno-prakticheskoj konferencii [Selected papers of the VI International Scientific Conference] (2017) (in Russian)

11. S.V. Litovkin, Yu.R. Pet'kova, Proceedings of the International Scientific Conference «Relevant issues of modern mechanical engineering», 433-435 (2015) (in Russian)

12. V.P. Grakhov, S.A. Mokhnachev, O.V. Borozdov, Fundamental research, 11-12, 2673-2676 (2014) (in Russian)

13. I. Hager, A. Golonka, R. Putanowicz, Procedia Engineering, 151, 292-299 (2016).

14. E. Lloret, A.R. Shahab, M. Linus, R.J. Flatt, F. Gramazio, M. Kohler, S. Langenberg, Computer-Aided Design, 60, 40-49 (2015)

15. T.T. Le, Cement and Concrete Research, 3, 558-566 (2012)

16. O.V. Demyanenko, Vestnik of TSUAB, 4 (63), 101-106 (2017) (in Russian)

17. A.V. Gorshkova, Suhie stroitel'nye smesi s modificirujushhej dobavkoj na osnove torfa [Dry construction mixes with a modifiing additive on the basis of peat], Candidate thesis, Tomsk State University of Architecture and Building, Tomsk (2015) (in Russian)

18. Yu.S. Sarkisov, Vestnik of TSUAB, 4, 226 - 234 (2012) (in Russian)

19. L.A. Urkhanova, Stroitel'nye materialy [Builind Materials], 8, 52-55 (2014) (in Russian)

20. E.V. Korolev, Stroitel'nye materialy - Nauka [Builind Materials - Science], 8, 2-4 (2006) (in Russian)

21. V.G. Hozin, Stroitel'nye materialy [Builind Materials], 2, 25-33 (2015) (in Russian)

22. E.E. Ezupenok, Soderzhanie himicheskih jelementov v torfah i torfjanyh pochvah juzhno-taezhnoj podzony Zapadnoj Sibiri [The content of chemical elements in peat and peat soils of the southern taiga subzone of Western Siberia], Candidate thesis, Tomsk State Pedagogical University, Tomsk 2005, (in Russian)

23. A.A. Guvalov, Stroitel'nye materialy [Builind Materials], 9, 94-95 (2013) (in Russian) 
24. G.I Berdov, Mezhdunarodnyj zhurnal prikladnyh i fundamental'nyh issledovanij [International Journal of Applied and Fundamental Research], 9, 87-91 (2010) (in Russian)

25. P.N. Kurochka, Engineering journal of Don, 1 (24) (2013) (in Russian) 